\title{
THE STRUCTURAL SOLUTIONS OF THE TIMBER ROOFS: JOINTS AND JOINING PLATES
}

UDC: $674.11: 692.42$

Original scientific paper

https://doi.org/10.18485/aeletters.2018.3.2.4

\author{
Jacek Selejdak ${ }^{1}$, Kinga Brózda ${ }^{1}$, Sebastian Kowański ${ }^{1}$ \\ ${ }^{1}$ Czestochowa University of Technology, Faculty of Civil Engineering, Czestochowa, Poland
}

\begin{abstract}
:
In the article the authors present the practical design solutions regarding to structural timber roofs, especially the carpentry joints. The selected factors and parameters which should be respected during the correct static scheme of the roof structure selection are presented. The main differences between the two widely used and visually similar static schemes of roof systems are listed: the rafter - collar tie and the rafter - doubled collar tie roofing systems. A concise comparison of the structural work of these systems is presented. Primarily, in the paper the selected joints and joining plates were discussed in detail. The most popular traditional solutions of used carpentry joints and the new, alternative ones are described. The advantages and disadvantages of discussed solutions are pointed, as well as the advices on their practical use in the construction industry. As a conclusion, based on the conducted research it can be stated that using the innovative solutions of joints and joining plates avoids the most common assembly errors and are a good solution for joining the structural elements of the timber roofs.
\end{abstract}

\section{ARTICLE HISTORY}

Received: 06.02.2018.

Accepted: 22.02.2018.

Available: 30.06.2018.

\section{KEYWORDS}

practical design solutions, timber structures, static scheme, roof systems, carpentry joints and connectors.

\section{INTRODUCTION}

For many people professionally connected with the construction industry, issues related to the construction of roof structures may turn out to be unattractive because, as they say, "everything in this field has already been discovered". However, it can be noticed that a large part of investors who dream about their own home are relatively often looking for information on the Internet forums, in order to avoid many technical and organizational mistakes. It will often be heard that in some region of the country has been a lot of roof covering damage as a result of impact of the atmospheric phenomena. Sometimes, a seemingly solidly made new roof was completely destroyed, while the one of 100 years - survived. Therefore, the question arises whether it is a pure accident, or perhaps a small construction detail had an impact on the destruction [1].

The oldest timber structures used to protect the interiors of the buildings from weather conditions such as rain or wind, resembled a simple rafter truss supported in the lower part of this element. Due to the lack of access to impregnation agents in the past, the natural methods were used to protect the timber against biological corrosion and had a significant impact on its durability $[1,2]$.

As a result, the builders at that time have paid the particular attention to such factors as:

$>$ proper season and air temperature at the time of felling of trees,

$>$ ensuring optimal humidity of the timber by seasoning,

$>$ careful debarking of timber.

The article presents practical design information regarding the timber structures, and especially woodworking joints. The selected traditional and alternative solutions of used carpentry joints are described. The advantages and disadvantages of those solutions are mentioned, as well as practical advice on their use. Moreover, the seemingly similar static scheme of roof system are presented and compared $[2,3]$. 


\section{THE SELECTED STATIC SCHEMES OF THE ROOF STRUCTURE}

The final form of the roof depends on the decision of designer and the investor. The investor decides on the type of roofing and on what kind of roof will cover the building (flat or pitched). Those preliminary findings affect the designer's work. The choosing a light covering, for example roofing sheet or bituminous shingle, causes that the roof truss can be made of elements with smaller crosssections than in the case when the roof will be covered with ceramic tiles [4]. However, considering the fact that the structure should be safe throughout its whole lifetime, the final shape of the roof should depend on the designer, who also takes into account other parameters of the structure, such as:

$>$ the height of the building (one-story house, or with an attic),

$>$ the shape of the roof,

$>$ the roof span,

$>$ the standard loads (depending on snow and wind load zones).

In the first place, during the design and practical considerations regarding the timber structures, the attention should be paid to the visual similarity between the rafter - collar tie roof system and the rafter - doubled collar tie roof system [4,5]. However, this is only an optical illusion. The basic elements of visual differences include the following elements:

$>$ the collar ties (beams) are single elements in each girder,

the doubled collar ties (beams) occur in pairs and are found only in full trusses (approx. at every third pair of rafters).

However, the more important design aspects of the roof structure are the differences consisting in the other specifics of work and functions that the given elements should perform. The properly executed collar tie is an element working in compression, which brings with it a significant design difficulty - the emergence of expansion forces, i.e. a horizontal support reactions. Therefore, in this type of roofing systems, laying the rafters on a wall plate (sill) in a traditional way, i.e. a wall plate is rarely anchored on a reinforced concrete tie beam, and connected by rafters, using a popular rafter nail is not enough. With such a solution, a very serious failure can occur even during the roof construction, because this solution does not provide an articulated non-movable support (it works like a spring support). Then, the structure of the roof will be destroyed by the disintegration of its elements, as shown in Fig.1. The shown connection is not able to transfer all the tensile forces - the majority of the structural elements began to work contrary to their intended use $[4,6]$.

The Fig. 2 and 3 show the static schemes of the both roof systems and the comparison of the work of the rafter - collar tie and the rafter - doubled collar tie roof systems under the influence of the self-weight. The comparative analysis indicates the differences in a boundary conditions of the support and the appearance of various values of internal forces (in this case the normal forces) in both systems. If a displacement occurs, and thus the reaction is not transferred to the elements located below, then it is possible to release the force and the appearance of failure $[7,8]$.

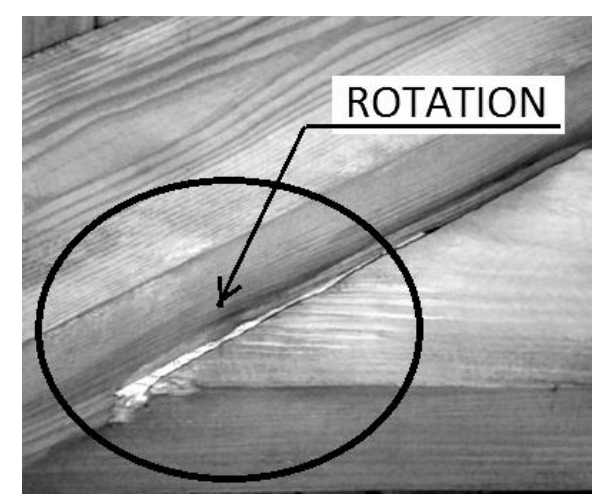

Fig. 1. The scheme of the rafter-wall connection [8]

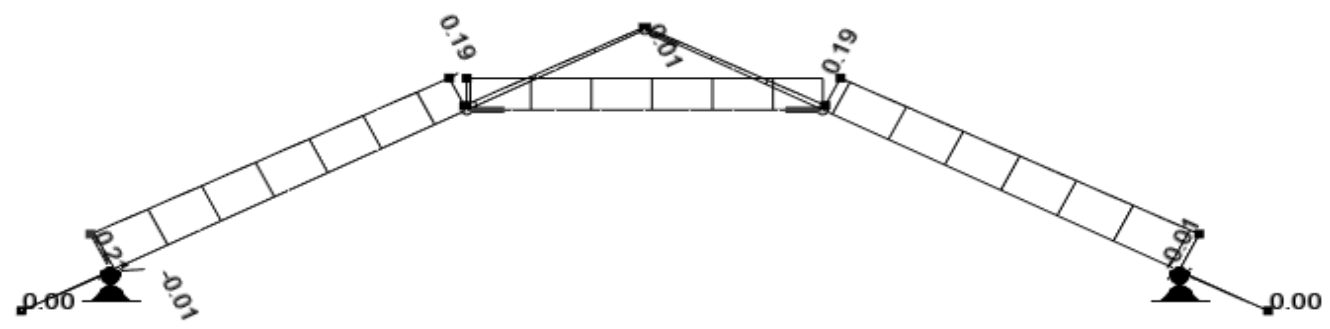

Fig. 2. The static scheme and the distribution of the axial forces [kN] of the rafter-collar tie system 


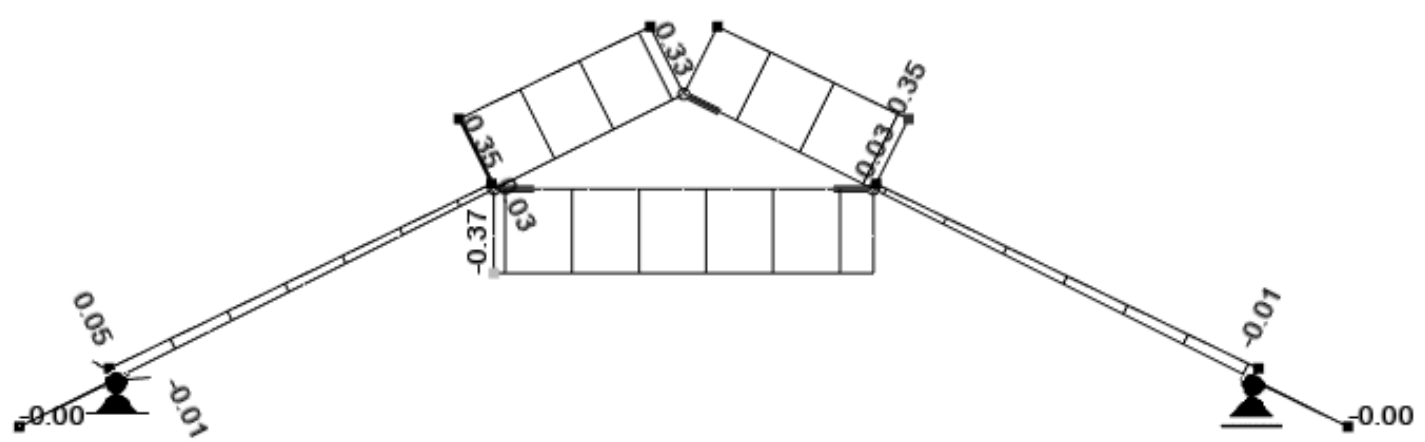

Fig. 3. The static scheme and the distribution of the axial forces [kN] of the rafter - doubled collar tie system

\section{CARPENTRY JOINTS}

The carpentry joints are a very important issue in the design of the timber structures. Although the correct performance of these details is not easy, it is quite often the contractors approach to use them without due diligence. It significantly reduces the strength of the entire construction, despite the fact that optimal cross-sections of individual timber support elements are used. Everywhere, where there are the connections of structural elements, the special care should be taken. In particular, it concerns the rafter-wall (sill) connections (Fig.4), which must transfer all loads from the roof and then transfer them to the loadbearing walls of the building $[4,9]$.

The most popular traditional combination is the use of the so-called rafter nail (Fig.5). The connectors of this type are still very commonplace among many carpenters and designers. Unfortunately, the main problem in the case of its use is the ordinary routine, which does not take into account the impact of all the loads, dimensions of the object, the type of coverage and the static scheme adopted for the calculation. Many contractors are not convinced by the innovative solutions to some stereotypes that conceal the main advantages of the new connectors, such as, among others, much higher load capacity $[2,4]$.

The connections made of the rafter nail have its drawbacks. The basic disadvantages include the small force that a given connector can carry. For example, the average shear strength of the rafter nail is not more than approximately $3 \mathrm{kN}$. Another disadvantage is the assembly of nails, which should be preceded by pre-drilling. Its lack, combined with inadequate humidity of timber, may lead to delamination of this material. In addition to the shear capacity, the tensile strength is an equally serious problem. This resistance is based solely on the friction forces between the metal connector and the timber element.

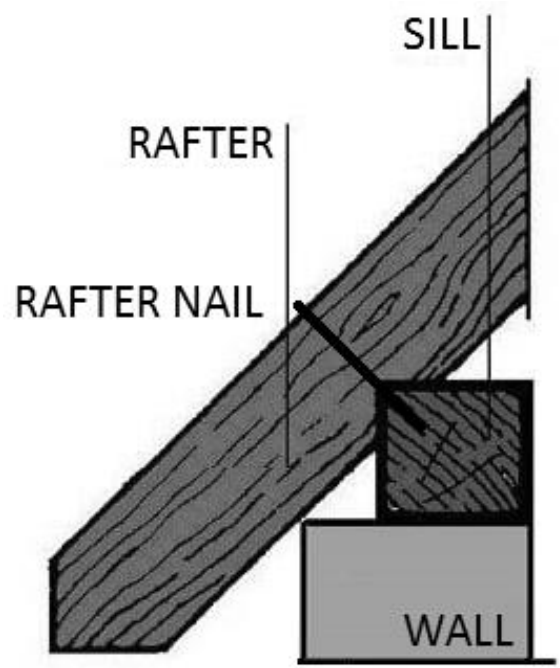

Fig. 4. The scheme of the rafter-wall connection

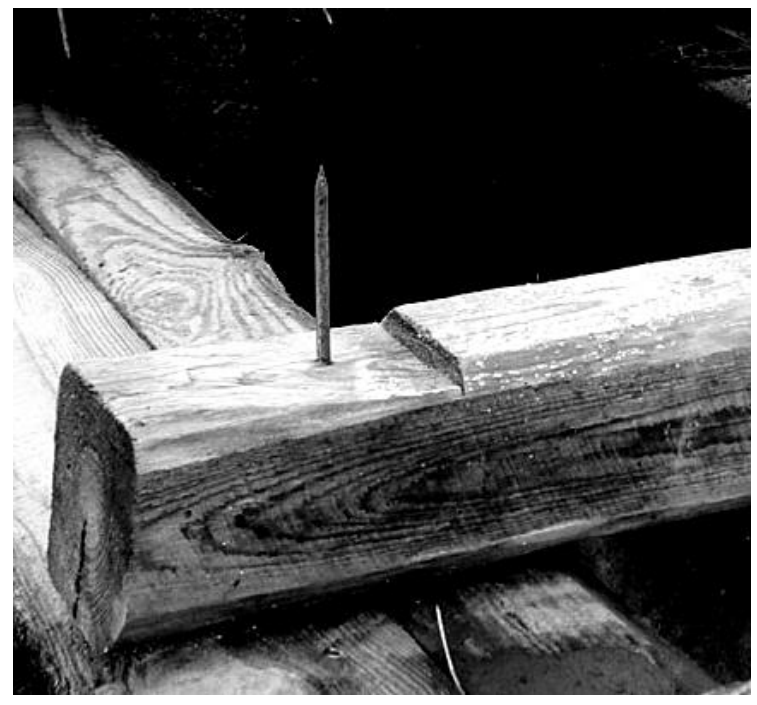

Fig. 5. The broken connection with rafter nail [8]

The friction force is relatively small, and the effects of the low friction (thus poor anchorage) are visible in places affected by the strong wind. It is the result of the fact that nails can be removed 
from the wall without a major problem. As a consequence, the entire roof slopes, in the case of strong winds, are transferred even several hundred meters. A slightly better solution may be the use of long steel screws. However, this solution does not guarantee

a significant increase in the load capacity of the connection [2].

\section{ALTERNATIVE SOLUTIONS FOR CARPENTRY CONNECTIONS}

After paying attention to the disadvantages resulting from the use of traditional carpentry joints, it is necessary to explain how to eliminate those failures. It is certainly a good solution to use a new type of carpentry joints, but in this case the selection of the correct connector is a very important issue. Apparently the two identicallylooking carpentry joints and nails can significantly differ in their work. Only the elements, which have a documented strength parameters, i.e. those that come from the recommended manufacturer and have the appropriate certificates, should be used for all kinds of structures. The parameters of this type of products are determined based on the special standard tests, the results of which are included in the technical approvals. The main difference is that the item coming from the production for sale may meet the assumed parameters, but may have a lower carrying capacity, e.g. by $50 \%$. In summary, connectors to be used in structural joints must have appropriate markings being the basis for taking into account their bearing capacity in the strength calculations $[10,11]$.

The next stage of correct use of carpentry joints is their proper assembly. In Fig.6 and 7, can be seen that the connections, which use theoretically similar joints with the same load capacity. However, due to the oversight of the constructor, one actually fulfilled its role and the other did not [12]. The contractor did not pay attention to the fact that the holes made in the sheet are not randomly arranged and the selection of connectors should be adapted to their proper purpose. The direct cause of the failure was the too large distance of nails in the first row from the bend line. It comes to similar oversights as in the timber timber connections and, may occur in the case of the timber - concrete connections. The case of such a combination is presented in Fig. 8 and 9.

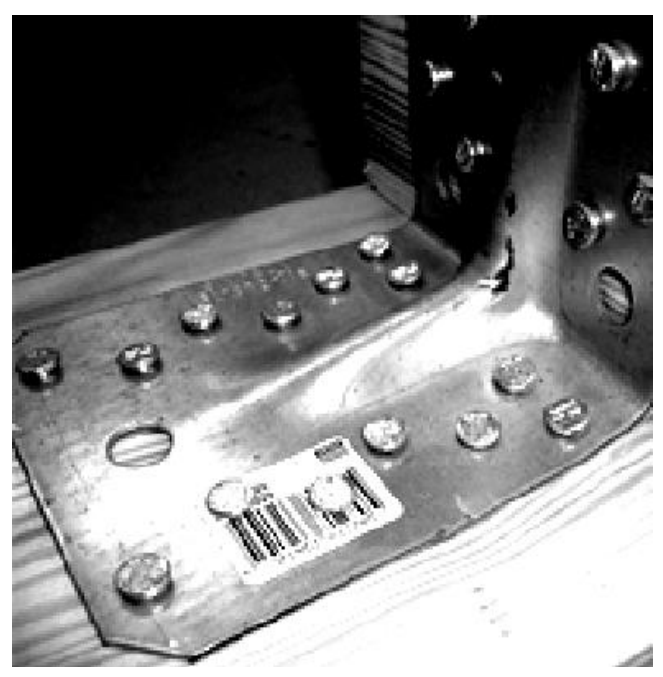

Fig. 6. Example of the fixing of carpentry joints in the timber - timber combination - the proper nails placement [8]

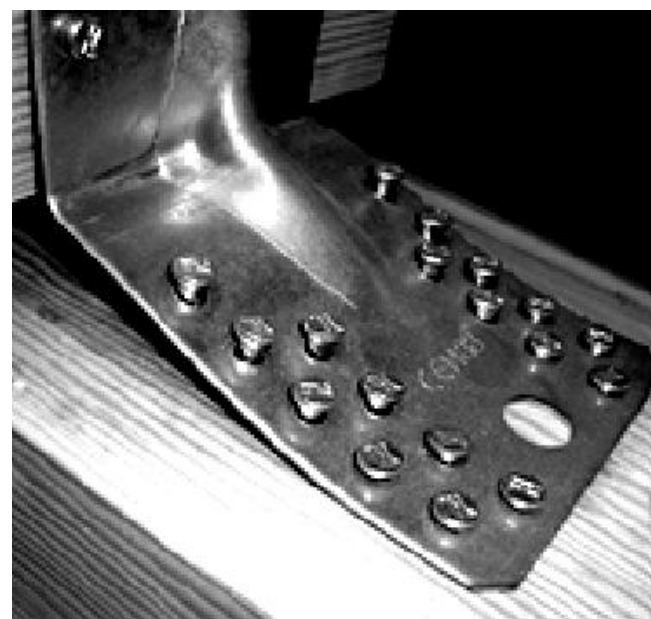

Fig. 7. Example of the fixing of carpentry joints in the timber - timber combination - the failure because of too large distance of the nails to the break line [8]

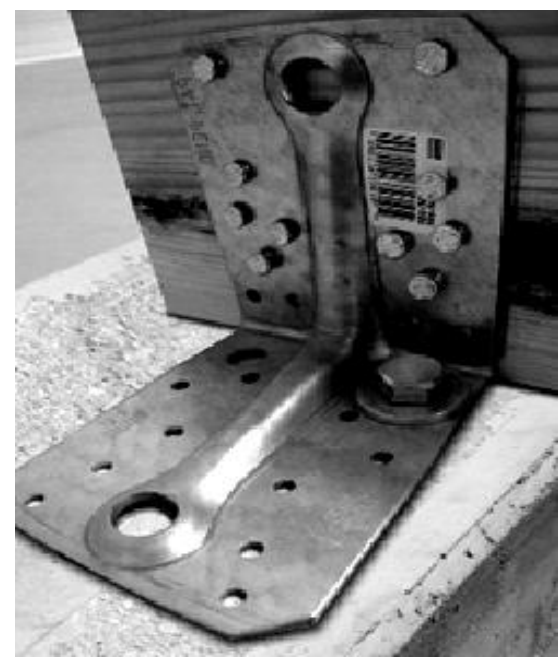

Fig. 8. Example of the fixing of carpentry joints in the timber - concrete combination - the proper placement of the nails and bolts [8] 


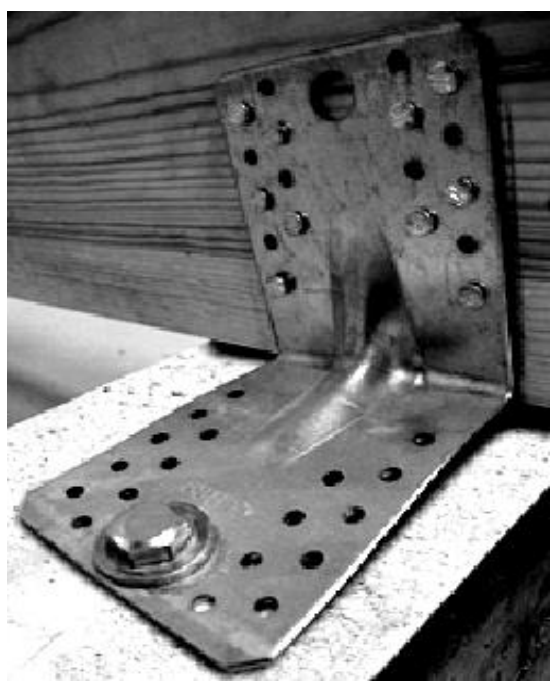

Fig. 9. Example of fixing of carpentry joints, a timber concrete combination - the failure because of too large distance of a bolt to the break line [8]

The use of that type of the angular connectors is advantageous because this solution has a good load capacity for the horizontal forces, as well as for the wind suction. In the joints where pairs of angles were used, the lifting capacity is equal approximately $17.8 \mathrm{kN}$, while the horizontal load capacity is over the value of $20 \mathrm{kN}$. This value is incomparably larger in relation to the load capacity of traditionally used nails. In Fig.10 an examples of the schematic use of the angular connectors are shown.
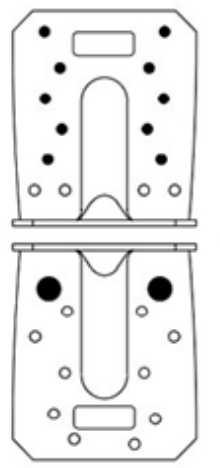

or
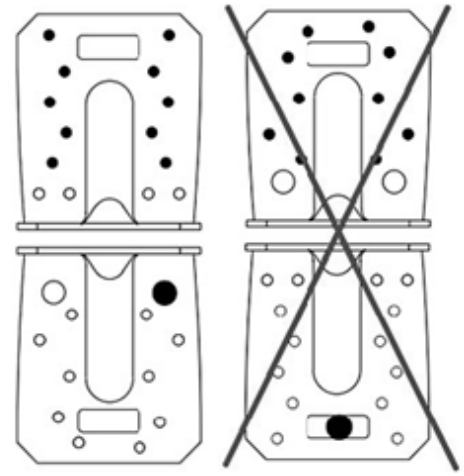

Fig. 10. The schematic examples of arrangements of the nails and screws [8]

In Fig.11 examples of universal angular connectors that can be used in both joints, timber - timber and timber - concrete combination of connection are presented.

In conclusion, it is important to place the corrugated nails in the corners of the joint as close as possible to the bend line. This method of the assembly avoids bending of the connecting element. The nails should not be hammered into all the openings, but used in such a way as to maintain the proper load capacity of the timber cross-section. The selection of the proper openings should be adapted to the cross-section of the timber, the direction of the fibers and the direction of the acting force. In the cross connections the nails should be placed diagonally. This arrangement of the connectors minimizes the influence of torsional forces on the connection. In addition, the method and type of drilling performed under the nails are also very important $[13,14]$.

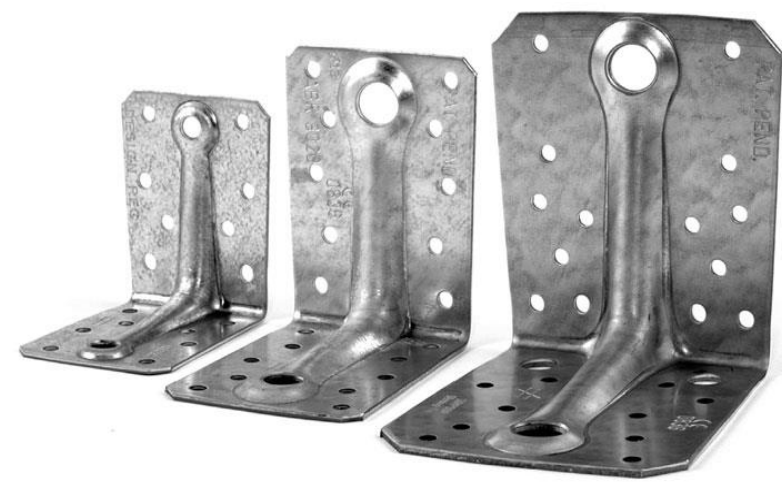

Fig. 11. The universal angular connectors [8]

\section{CONCLUSION}

The roof is not only the element of the building's cover, but most of all it is the structural system. Many a time for the destruction or survival of structures during the strong winds, small construction detail affected. Nowadays the examples of new and alternative connections, which are presented in this article, should become as typical solutions and stay permanently in the design and implementation areas. The presented facts should effectively dispel all the fears and stereotypes circulating around these types of joints. Those fears are most often the result of lack of the knowledge and appreciation of the possibilities of new construction solutions. Taking into account the increase in the rapidity of atmospheric phenomena, the discussed connectors are the right tools that can realistically reduce the failures of the roof constructions. However, it is important to remember the basic rules of the proper assembly of the carpentry joints, because the consequences of incorrect arrangement of the nails and screws in the connecting element can lead to the failure. Following the generally applicable rules will avoid the most common assembly errors. Moreover, based on the conducted research, it can be stated with great conviction that those innovative solutions are a good forecast for the future. 


\section{REFERENCES}

[1] J. Jasieńko,T. Nowak, A. Karolak, Historical carpentry joints. Wiadomosci Konserwatorskie - Journal of Heritage Conservation, 40 (-), 2014: 58-82.

[2] Z. Gęsiński, Basic carpentry joints in timber rafter frames. Warstwy - Dachy i Ściany, 2 (-), 2008: 37-41. (In Polish)

[3] H. McArthur, D. Spalding, Timber and timber products. Engineering Materials Science Properties, Uses, Degradation, Remediation, Chapter in book No.12, 2004: 406-464.

https://doi.org/10.1533/9781782420491.406

[4] J. Hoła, P. Pietraszek, K. Schabowicz, Calculation of the construction of buildings erected traditionally. Dolnoślqaskie Wydawnictwo Edukacyjne, Wrocław, 2013. (In Polish)

[5] P Witomski, Maintenance and durability of timber structures. Budownictwo i Architektura, 14 (4), 2015: 157-164.

[6] M. Chojnacka, Making connections and carpentry joints. Instytut Technologii Eksploatacji - Państwowy Instytut Badawczy, Radom, 2006. (In Polish)

[7] R. Ciesielski, A. Kwiecień, R. Pęcherski, B. Zając, The use of susceptible joints in structures working in the new determined state of static equilibrium. $50^{\text {th }}$ Jubilee Scientific Conference of the Civil and Water Engineering Committee of PAN and PZITB "Krynica 2004", 12 ${ }^{\text {th }}$ September, 2004, Warszawa-Krynica, Poland, pp.257-266.

[8] The promotional materials of the Simpson Strong-Tie company. http://strongtie.pl/

[9] J.M. Branco, T. Descamps, Analysis and strengthening of carpentry joints. Construction and Building Materials, 97 (-), 2015: 34-47. http://dx.doi.org/10.1016/j.conbuildmat.2015.05.089

[10] A. Kysiak, K. Regulska, Carpentry joints in traditional and modern timber constructions of roof trusses. Scientific Books of Czestochowa University of Technology - Civil Engineering series, 19 (169) 2013: 61-68.

[11] M. Major, J. Różycka, Steel connectors in timber constructions. Scientific Books of Czestochowa University of Technology - Civil Engineering series, 19 (169), 2013: 107-114.

[12] P. Palma, H. Garcia, J. Ferreira, J. Appleton, H. Cruz, Behaviour and repair of carpentry connections - Rotational behaviour of the rafter and tie beam connection in timber roof structures. Journal of Cultural Heritage, 13 (3), 2012: S64-S73.

http://dx.doi.org/10.1016/i.culher.2012.03.002

[13] B. Kisielewicz, D. Kram, Fasteners and connections in modern timber constructions with a pass to various architectural forms. Architektura, 108 (2-A/2), 2011: 295-302. (In Polish)

[14] P. Gogojewicz, Practical roofing advices. Złq̨cza ciesielskie certyfikowane i niecertyfikowane

http://fachowydekarz.pl/

\section{ACKNOWLEDGEMENT}

The words of gratitude to the Simpson Strong$\mathrm{Tie}^{\circledR}$ company for sharing materials regarding to the innovative carpentry joints.

\section{NOTE:}

The shorter version of this research was presented at the "23" International Seminar of PhD Students SEMDOK 2018", 24-26 January 2018, Western Tatras, Zuberec, Slovakia. 